\title{
A Novel Tool for Detecting Amyloid Deposits in Systemic Amyloidosis In Vitro and In Vivo
}

\author{
Yukio Ando, Katsuki Haraoka, Hisayasu Terazaki, Yutaka Tanoue, \\ Kensuke Ishikawa, Shoichi Katsuragi, Masaaki Nakamura, Xuguo Sun, \\ Kazuko Nakagawa, Kazumi Sasamoto, Kazuhiro Takesako, Takashi Ishizaki, \\ Yutaka Sasaki, and Katsumi Doh-ura
}

\begin{abstract}
Department of Laboratory Medicine (YA, MN, XS) and Department of Gastroenterology and Hepatology (KH, HT, YS), Kumamoto University School of Medicine, Kumamoto, and Department of Pharmacology and Therapeutics (YT, KN, TI), Graduate School of Clinical Pharmacy, Kumamoto University, Kumamoto, and Department of Neuropathology (KI), Neurological Institute, Graduate School of Medical Sciences, Kyushu University, Fukuoka, Division of Prion Protein Biology (KD), Department of Prion Research, Tohoku University Graduate School of Medicine, Sendai, and Department of Psychiatry (SK), Kikuchi National Hospital, Koshi-machi, Kikuchi-Gun, Kumamoto, and Dojin Chemical Company (KS, KT), Mashiki, Kamimashiki, Kumamoto, Japan
\end{abstract}

SUMMARY: We synthesized (trans,trans)-1-bromo-2,5-bis-(3-hydroxycarbonyl-4-hydroxy)styrylbenzene (BSB) and used this compound to detect amyloid fibrils in autopsy and biopsy samples from patients with localized amyloidosis, such as familial prion disease, and systemic amyloidosis, such as familial amyloidotic polyneuropathy, amyloid A (AA) amyloidosis, light chain (AL) amyloidosis, and dialysis-related amyloidosis. BSB showed reactions in all Congo red-positive and immunoreactive regions of the samples examined in the study, and some amyloid fibrils in the tissues could be detected more precisely with BSB than with the other methods. In the mouse model of AA amyloidosis, injected BSB reacted with amyloid in all regions in the serial sections in which Congo red staining was positive. A highly sensitive $27-\mathrm{MHz}$ quartz crystal microbalance analysis revealed that BSB showed a significant affinity for amyloid fibrils purified from familial amyloidotic polyneuropathy and dialysis-related amyloidosis samples and suppressed formation of transthyretin amyloid in vitro. These results suggest that BSB may become a valuable tool for detection of amyloid deposits in amyloidosis and of the mechanism of amyloid formation. (Lab Invest 2003, 83:1751-1759).

\begin{abstract}
$P$ rogress in molecular genetics and biochemical methodologies has led to the identification of various types of amyloidosis and their amyloidogenic precursor proteins (Benson, 1995; Ikeda et al, 2002; Saraiva, 2001; Tan and Pepys, 1994; Tan et al, 1995). Thus far, 24 different amyloidogenic proteins have been identified; however, the mechanism of amyloid formation has been elucidated in only several types of amyloidosis (Ando et al, 2002; Benson et al, 1993; Benson and Uemichi, 1996; Pepys et al, 1993; Soutar et al, 1992; Westermark et al, 2002). One of the most important steps in the diagnosis of the specific type of amyloidosis is detection of amyloid deposits in tis-
\end{abstract}

DOI: 10.1097/01.LAB.0000101701.87433.C5

Received February 20, 2003.

$Y A$ and KH contributed equally to the study. This work was supported by grants from the Amyloidosis Research Committee and the Pathogenesis, Therapy of Hereditary Neuropathy Research Committee, Surveys and Research on Specific Disease, the Ministry of Health and Welfare of Japan, Charitable Trust Clinical Pathology Research Foundation of Japan, and Grants-in-Aid for Scientific Research (C) 13670655 and (B) 15390275 from the Ministry of Education, Science, Sports and Culture of Japan. Address reprint requests to: Dr. Y. Ando, Department of Laboratory Medicine, Kumamoto University School of Medicine, Japan. sues. It is not easy to predict the presence of these amyloid deposits on the basis of patients' clinical manifestations, that is, without histopathologic materials. Thus, amyloidosis is sometimes diagnosed after the death of the patients (Ishihara et al, 1989).

In systemic amyloidosis, such as familial amyloidotic polyneuropathy (FAP), AA amyloidosis, AL amyloidosis, and dialysis-related amyloidosis (DRA), biopsy samples are often obtained from the gastrointestinal tract and abdominal fat to make the diagnosis (Guy and Jones, 2001; Kaplan et al, 1999; Masouye, 1997) because amyloid deposits are usually found in these tissues at the early stage of the disease. However, in certain cases it is sometimes difficult to make the diagnosis using only the biopsy samples, because the pattern of amyloid deposition in the body varies in each individual (Ishihara et al, 1989). In addition, biopsy for diagnostic purposes cannot usually be performed in patients with localized amyloidosis, such as in Alzheimer's disease and endocrine amyloidosis (Westermark and Westermark, 2000). Diagnosis at the early stage of amyloidosis might be possible if a tool were available that incorporated real-time amyloid monitoring, such as radioisotopelabeled scintigraphy (Hawkins et al, 1990; Puille et al, 2002). 
Among several histopathologic methods with stains such as Congo red, Pagoda red, and thioflavin S, Congo red staining is one of the most popular detection methods of amyloid deposits in tissues (Puchtler and Sweat, 1965; Westermark et al, 1999). Congo red is a hydrophilic chemical agent that binds to amyloid fibrils in vitro (Benditt et al, 1970; Westermark et al, 1999). Apple green birefringence under polarized light after Congo red staining is the most reliable evidence of the presence of amyloid fibrils in biopsy and/or autopsy materials from patients with amyloidosis (Sipe and Cohen, 2000; Westermark et al, 1999), although Congo red-stained histochemical sections are not always easy to interpret. However, the Congo red stain cannot be used for in vivo studies because it has toxic effects in the human body (Bi et al, 1992; Case et al, 1954; Giger et al, 1974; Giger and Zbinden, 1974; Kennelly et al, 1984; Zenser et al, 1998). Chrysamine G, a Congo red derivative with a similar molecular structure used for the same purpose as Congo red, has the same limitations (Dezutter et al, 1999, 2001a; Klunk et al, 1995, 1998). To overcome these problems, we must have a new tool for examination of amyloid deposition in tissues.

(trans, trans)-1-bromo-2,5-bis-(3-hydroxycarbonyl4-hydroxy)styrylbenzene (BSB), which has been found to bind to amyloid plaques in postmortem samples of brains from patients with Alzheimer's disease, is also a Congo red derivative and has been the focus of recent attention (Klunk et al, 1994; Schmidt et al, 2001; Skovronsky et al, 2000; Zhuang et al, 2001a, 2001b). Because this compound is lipophilic, it can traverse the blood-brain barrier, and it binds to amyloid fibrils in the brain when it is injected intravenously into transgenic mice with Alzheimer's disease (Skovronsky et al, 2000). Moreover, this compound can detect cell inclusion bodies derived from $\alpha$-synclein (Schmidt et al, 2001). However, no studies have addressed the question of whether the compound could become a useful tool for detection of amyloid deposits in systemic amyloidosis. Various plasma proteins in the systemic circulation may disturb the binding of BSB to amyloid fibrils in tissues.

In this study, we carefully checked the reactivity of BSB with amyloid fibrils found in various types of systemic amyloidosis and a familial type of prion disease. To determine the usefulness of the compound in vivo, we also examined BSB reactivity in amyloid deposits in mice in which $\mathrm{AA}$ amyloidosis had been induced. In addition, we investigated the affinity of BSB for amyloid fibrils and the inhibitory effect of BSB on formation of transthyretin (TTR) amyloid fibrils in vitro by means of a highly sensitive 27-MHz quartz crystal microbalance (QCM) (Matsuno et al, 2001; Okahata et al, 1998) and electron microscopy, respectively.

\section{Results}

\section{BSB Reactivity with Amyloid in Deposits in Various Types of Amyloidosis}

BSB reacted with amyloid in deposits in familial prion disease and in various systemic amyloidoses such as
FAP, AA, AL, and DRA (Fig. 1). Except for reactions in familial prion disease, BSB reactions were noted in lesions in which the antibodies also showed a positive reaction. Compared with the sensitivity of Congo red staining, the sensitivity of BSB was more precise, with a greater contrast in the BSB-positive areas in the tissues.

\section{BSB Reactivity with Amyloid in Deposits in AA Amyloidosis In Vivo}

We injected BSB into mice in which $A A$ amyloidosis had been induced. We examined spleen samples and found that 24 hours after the injection of BSB into the mice, BSB-positive lesions were not obviously detected. However, 48 hours after the injection, BSBpositive lesions were clearly detected in both tissues. BSB reactions were seen in all lesions in the serial sections in which positive Congo red staining was confirmed under polarized light. Figure 2 shows amyloid deposits stained by BSB in vivo.

\section{Affinity of BSB or Congo Red for Amyloid Fibrils}

The frequency of the QCM responding to BSB decreased over time, which indicated that BSB had significant affinity for the amyloid fibrils purified from intestinal DRA and vitreous FAP samples. However, neither wild-type TTR nor the variant TTR showed any affinity for BSB (Fig. 3A). In a comparison of amyloid fibrils in the FAP and DRA samples, BSB showed a stronger affinity for DRA amyloid fibrils than for FAP amyloid fibrils.

BSB exhibited a strong affinity for amyloid fibrils: the amount of BSB bound to the amyloid was greater than the amount of Congo red bound to amyloid (M[BSB $]_{\max }$ : $266 \mathrm{ng} / \mathrm{cm}^{2}$, and M[Congo red] ${ }^{\max }$ : $157 \mathrm{ng} / \mathrm{cm}^{2}$ ), whereas the affinity of BSB for amyloid was weaker than that of Congo red (BSB: $K_{A}=5.66 \times 10^{5} / \mathrm{M}, K_{D}=1.76$ $\mu \mathrm{M}$; Congo red: $\mathrm{K}_{\mathrm{A}}=2.17 \times 10^{6} / \mathrm{M}, \mathrm{K}_{\mathrm{D}}=0.46 \mu \mathrm{M}$ ) (Fig. 3 , B and C).

\section{Inhibitory Effect of BSB on Amyloid Formation}

Electron microscopic analysis of the morphology of incubated TTR revealed that the fibrils in the absence of BSB were straight, nonbranched filament structures with helical periodicity and close to an authentic structure of amyloid fibrils (Fig. 4A). In comparison, the fibrils in the presence of BSB had irregularly shortcurled shapes, and the morphology of these fibrils was clearly distinct from that of typical amyloid fibrils (Fig. 4B).

\section{Discussion}

We demonstrated herein that BSB clearly reacted with amyloid in all amyloid deposits in the samples examined both in vitro and in vivo. Obvious BSB reactions with amyloid were noted, and the sensitivity of BSB for amyloid was better than that shown by Congo red. Although we could not find any Congo red-negative or precursor protein aggregate-positive lesions, so- 
A a

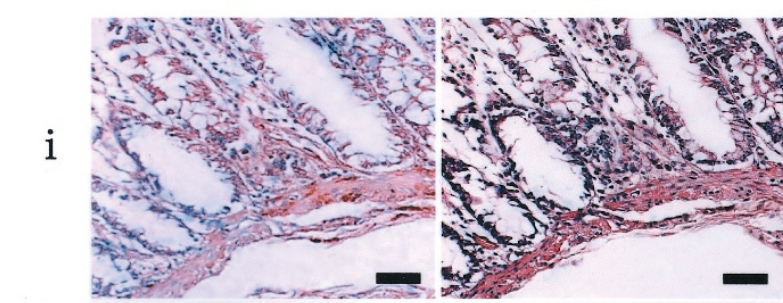

ii

iii
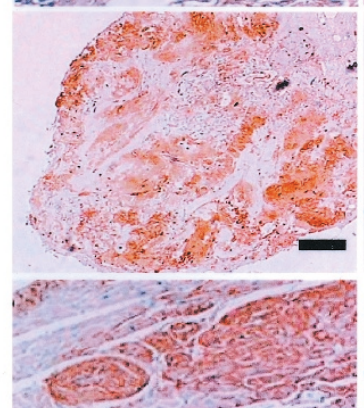

iii

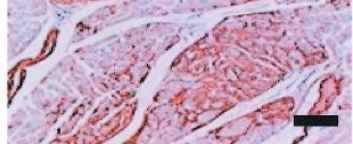

iv
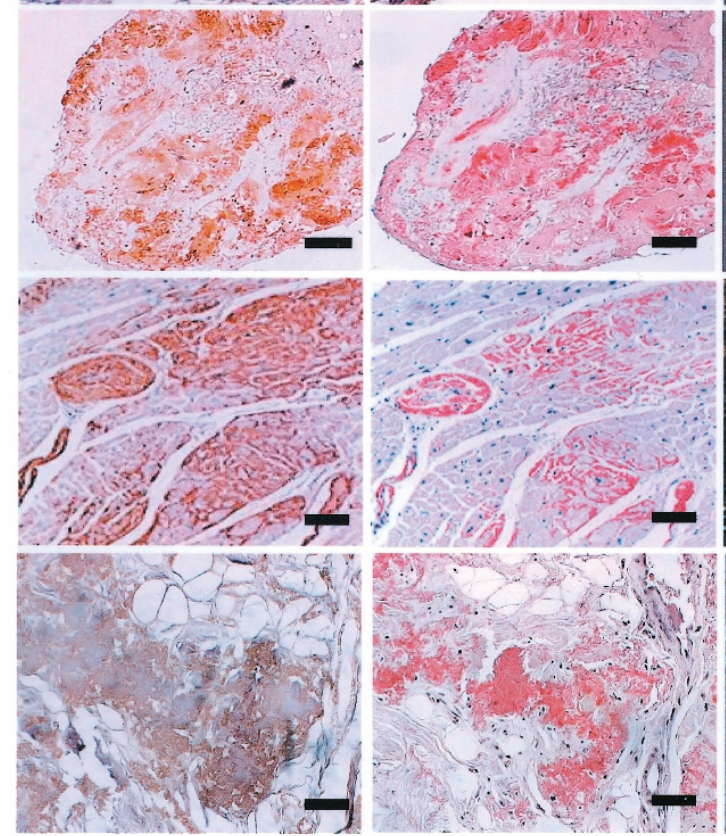

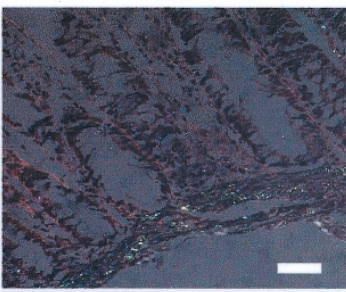

c

d


B

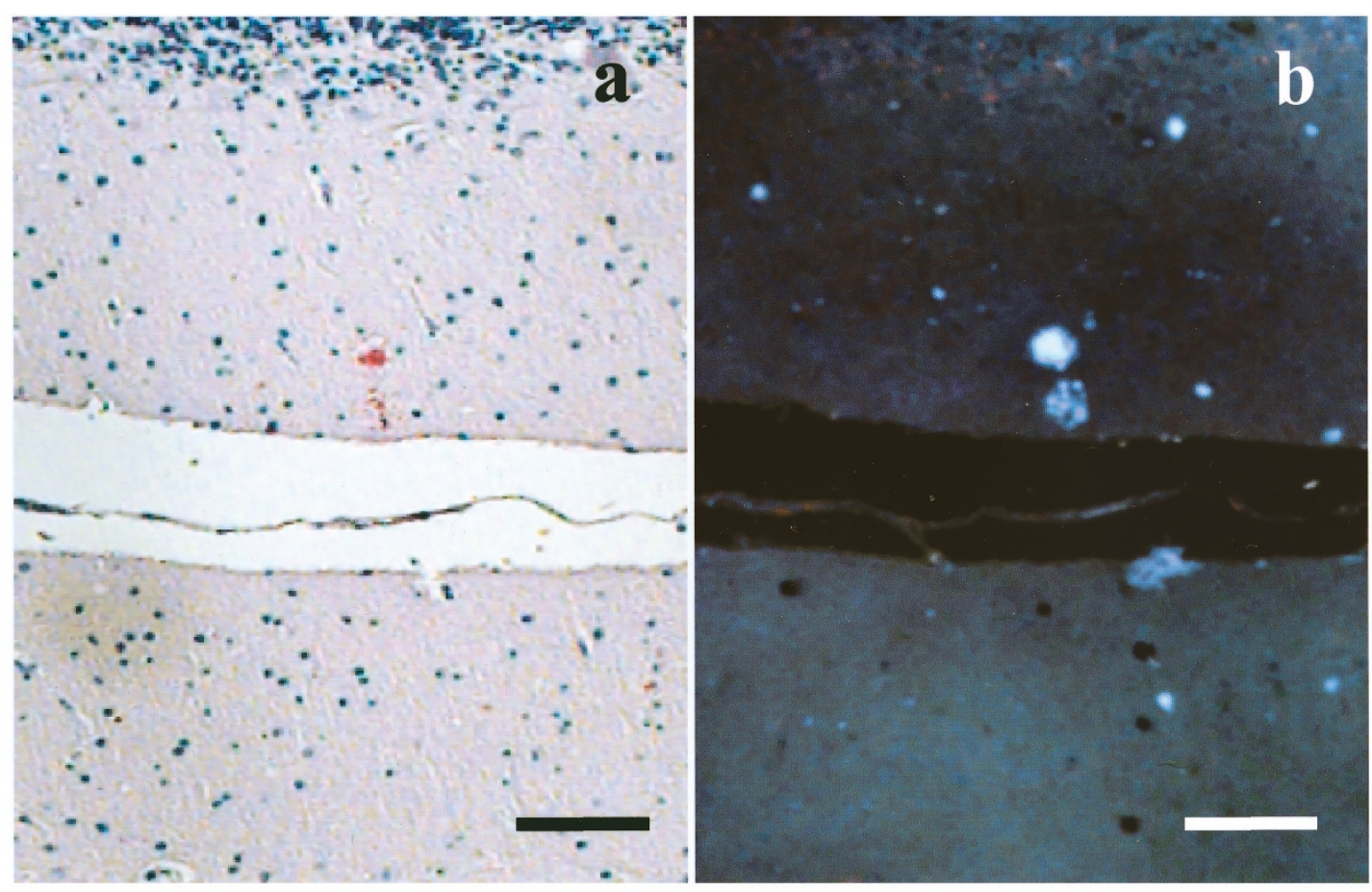

Figure 1.

(trans,trans)-1-bromo-2,5-bis-(3-hydroxycarbonyl-4-hydroxy)styrylbenzene (BSB) reactivity in various kinds of amyloidosis. Paraffin-embedded samples from patients with systemic amyloidosis (A) and familial prion disease (B). A: a, Immunohistochemical staining for amyloidogenic proteins with antibodies as described in the text. b and c, Staining with Congo red with hematoxylin and polarized light photographs, respectively. d, BSB staining. Row $i$ : familial amyloidotic polyneuropathy (FAP), scale bars $=10 \mu \mathrm{m}$; row ii: dialysis-related amyloidosis (DRA), scale bars $=50 \mu \mathrm{m}$; row iii: AA amyloidosis, scale bars $=100 \mu \mathrm{m} ;$ row iv. AL amyloidosis, scale bars $=200 \mu \mathrm{m}$. B: a, Staining with Congo red with hematoxylin of familial type of prion disease; $b$, its BSB staining. Scale bars $=100 \mu \mathrm{m}$. 

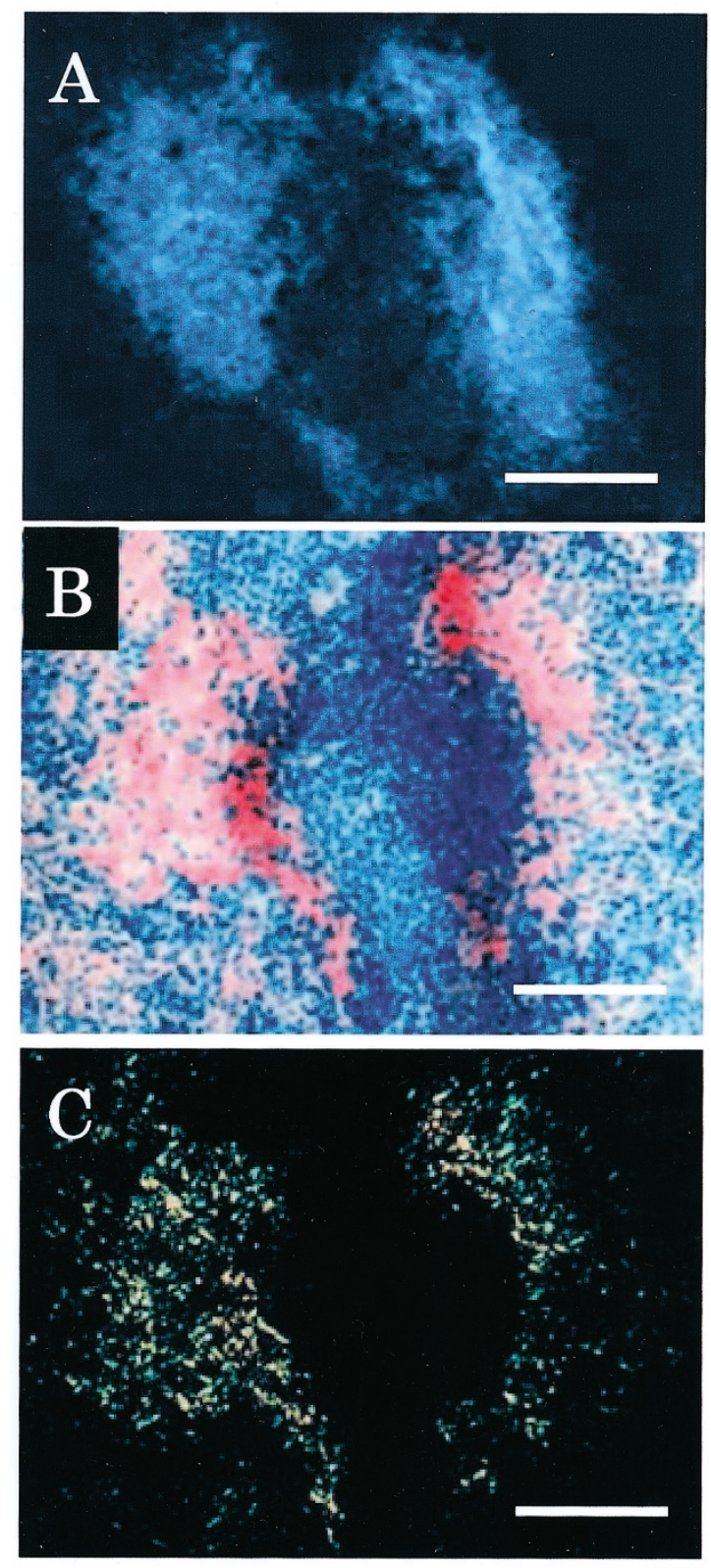

Figure 2.

BSB reactivity with amyloid in vivo. A, Microscopy of a spleen section from a BSB-injected mouse with AA amyloidosis. Fluorescence of BSB was observed under UV light. B and C, Staining with Congo red with hematoxylin and polarized light photograph, respectively. Scale bars $=150 \mu \mathrm{m}$.

called preamyloid state lesions, the dye might react with such lesions. When the color of the Congo red staining is close to the original color of tissues examined (Fig. 1B) or the amount of amyloid is small or scarce, we sometimes could not distinguish the presence or absence of amyloid deposition. In contrast, BSB examined under UV light had a whitish blue color, so we could clearly differentiate the amyloid deposits from the nonamyloid-containing tissues.

Comparison of BSB reactivity with staining of antibodies for amyloidogenic proteins revealed the same staining patterns for BSB and antibodies. BSB also reacted with amyloid in deposits in a brain sample from a patient with familial prion disease, a disease in which amyloid plaques were found in the brain, similar to amyloid deposits in the brain found in Alzheimer's disease (Skovronsky et al, 2000).

However, in samples from patients with a nonfamilial type of prion disease, which shows no amyloid plaques in the brain, no BSB-positive lesions were obtained (data not shown). These results suggest that BSB staining is useful for detecting amyloid clusters predominantly in systemic amyloidotic samples.

In systemic amyloidoses such as FAP, AA, AL, and DRA, most of the diagnostic methods are invasive (Guy and Jones, 2001; Ishihara et al, 1989; Kaplan et al, 1999; Masouye, 1997), with biopsy of the gastrointestinal system, abdominal fat, or sural nerves often used. However, amyloid deposition is not uniform in all forms of systemic amyloidosis (Ishihara et al, 1989; Tan and Pepys, 1994). Sometimes, no amyloid deposits can be observed in biopsy materials (Ishihara et al, 1989), although it is suspected that the disease process of amyloidosis has already started. In vivo realtime monitoring methods (Hawkins et al, 1990; Puille et al, 2002) would be beneficial for making the diagnosis of amyloidosis.

Serum amyloid $\mathrm{P}$ component (SAP) scintigraphy (Hachulla et al, 1994, 1996; Hawkins et al, 1990; Rydh et al, 1998; Saile et al, 1993) has been used to detect amyloid deposits in patients, because SAP is commonly found in amyloid deposits in all types of amyloidosis. Although SAP scintigraphy has made an invaluable contribution to diagnosis and is to date the only safe method, a nonspecific SAP reaction in the liver and kidneys is sometimes noted (Hawkins et al, 1990; Puille et al, 2002). Moreover, purification of SAP protein is difficult, because the molecule easily binds to various plasma and tissue proteins (Hawkins et al, 1990; Tan and Pepys, 1994). Scintigraphy with technetium-99m 3,3-diphosphono-1,2-propanodicarboxylic acid ( ${ }^{99 m}$ Tc-DPD) may be useful, but it has revealed amyloid deposits of only FAP (Puille et al, 2002). In addition, scintigraphy with ${ }^{99 \mathrm{~m}} \mathrm{Tc}$-labeled monoamidemonoaminedithiol chrysamine $G$ was useful in chickens with amyloid arthropathy, but no data on human amyloidosis or other types of amyloidosis in animal models in vivo were provided (Dezutter et al, 2001b). In addition, the labeling of compounds to ${ }^{99 \mathrm{~m}} \mathrm{Tc}$ for imaging must be conducted under conditions that use covalent chelating agents so that no separation of the label from the nuclide occurs in vivo (Moran, 1999).

The possibility of using BSB for scintigraphy in the brain has been proposed (Skovronsky et al, 2000). As demonstrated in Figure 2, after intravenous BSB injection into mice, BSB reactivity showed a significant colocalization with amyloid deposits stained by Congo red. In contrast, we found no accumulation of Congo red in amyloid deposits after Congo red injection into mice, although most of the mice died within several hours (data not shown). In addition, it has been well documented that Congo red has toxic effects, especially on platelets (Giger et al, 1974; Giger and Zbinden, 1974). Moreover, Congo red as well as chrysamine $G$ is classified into a group of azo dyes that contain a benzidine structure (Kennelly et al, 
A

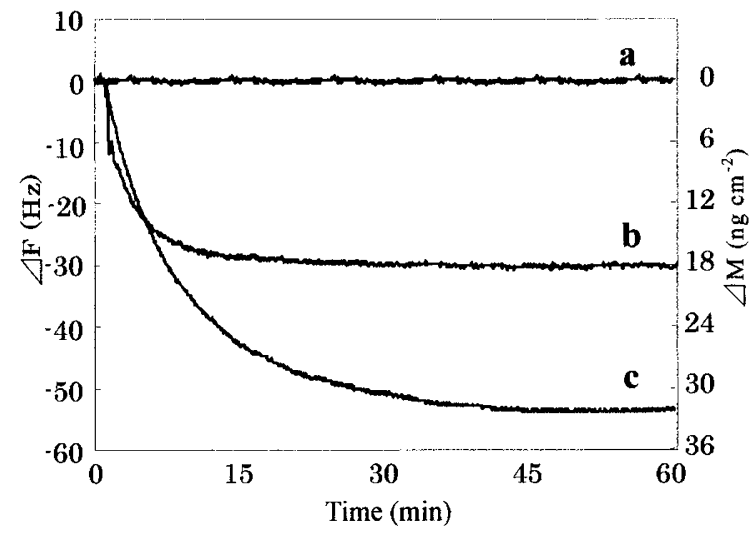

B

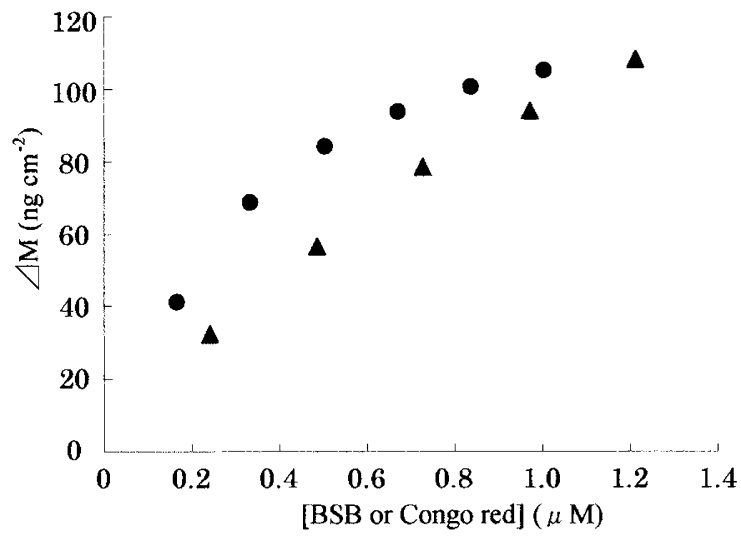

C

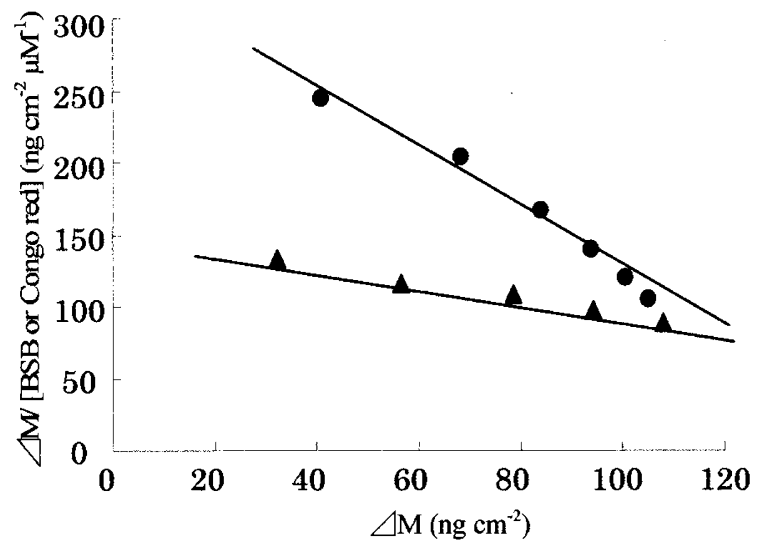

Figure 3.

A, Affinity of BSB for FAP or DRA amyloid fibrils and for transthyretin (TTR). Time courses of frequency changes $(\Delta \mathrm{F})$ of the quartz crystal microbalance (QCM) directory immobilized with FAP or DRA amyloid fibrils or with TTR were demonstrated. BSB dissolved in 10\% dimethyl sulfoxide (DMSO) was added into a buffered solution (10 mm Tris- $\mathrm{HCl}, 10 \%$ DMSO, $\mathrm{pH} 7.4,25^{\circ} \mathrm{C}$ ), at a final concentration of $1.45 \mathrm{nmol}$. Frequency changes $(\triangle \mathrm{F})$ of the QCM were converted into $\mathrm{QCM}$ binding amount $(\Delta \mathrm{M})$ according to the Sauerbrey Equation $\left(\Delta \mathrm{F}(\mathrm{Hz})=0.6 \mathrm{ng} / \mathrm{cm}^{2}\right)$ (Sauerbrey, 1959). a, TTR; b, FAP amyloid fibrils; c, DRA amyloid fibrils. B, Binding behavior of DRA amyloid fibrils depending on the concentration of BSB or Congo red. Increasing $\triangle \mathrm{M}$ by administration of BSB or Congo red into the solution in each time spot (10 mM Tris- $\left.\mathrm{HCl}, 10 \% \mathrm{DMSO}, \mathrm{pH} 7.4,25^{\circ} \mathrm{C}\right)$ resulted in a typical saturation binding curve [BSB concentrations: $1.45-7.27 \mathrm{nmol}$ in $6 \mathrm{~mL}(0.24-1.21 \mu \mathrm{m})$; Congo red concentrations: $1.00-6.03 \mathrm{nmol}$ in $6 \mathrm{~mL}(0.41-2.46 \mu \mathrm{m})]$. Closed circles $=$ Congo red; closed triangles $=\mathrm{BSB}$. C, Scatchard plot of affinities of BSB or Congo red for DRA amyloid fibrils

$$
\begin{gathered}
\Delta \mathrm{M} /[\text { BSB or Congo red }]=\Delta \mathrm{M}_{\max } / \mathrm{K}_{\mathrm{D}}-\Delta \mathrm{M} / \mathrm{K}_{\mathrm{D}} \\
\qquad \mathrm{K}_{\mathrm{A}}=1 / \mathrm{K}_{\mathrm{D}}
\end{gathered}
$$

Scatchard plots of the data in $\mathrm{B}$ gave a simple straight line according to Equation 1. Association constants $\left(K_{\mathrm{A}}\right)$ and the maximum binding amount $\left(\Delta \mathrm{M}_{\text {max }}\right)$ to $\mathrm{DRA}$ amyloid fibrils were calculated from the slope and the intercept of the $\mathrm{x}$-axis in the plot, respectively. Closed circles $=$ Congo red; closed triangles $=\mathrm{BSB}$. 


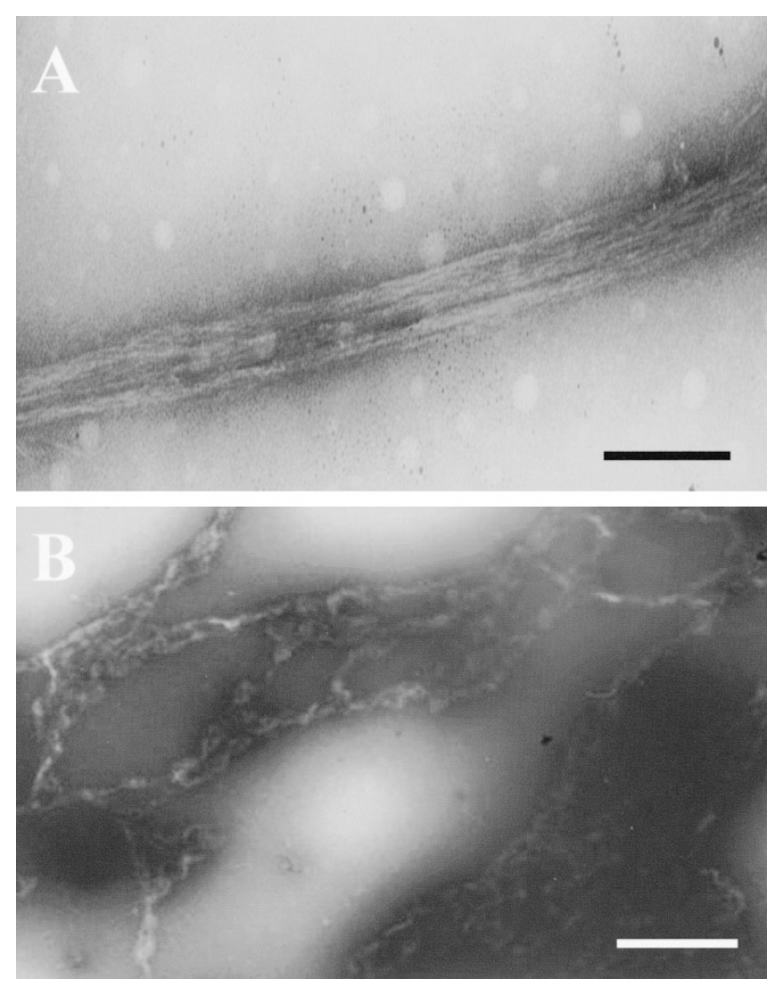

Figure 4.

Inhibitory effect of BSB as assessed by electron microscopy. Electron micrographs of the morphology of incubated wild-type TTR in the absence of BSB (A) and in the presence of BSB (B), as described in "Materials and Methods." Nonbranched helical filament structures were seen in the condition of $A$, and branched, short-curled fibrillar substances were seen in the condition of B. Scale bars $=30 \mathrm{~nm}$.

1984; Zenser et al, 1998; Zhuang et al, 2001a, 2001b). Compounds possessing the benzidine structure show carcinogenic effects when administered in vivo $(\mathrm{Bi}$ et al, 1992; Case et al, 1954). In contrast to Congo red, BSB may be beneficial in scintigraphic studies of systemic amyloidosis in humans, because it has no benzidine structure and can be easily modified at the Br position of the BSB molecule (Zhuang et al, 2001a, 2001b).

Additional effects of BSB-its affinity for amyloid and its inhibition of amyloid formation-were also studied. Figure 3 indicates the affinity of BSB for TTR, FAP amyloid fibrils, or DRA amyloid fibrils. QCM is a new tool for measuring the affinity of a protein for a protein, a protein for a DNA, and/or a protein for a chemical compound (Matsuno et al, 2001; Okahata et al, 1998). Our results confirmed the strong affinity of BSB for amyloid fibrils but not for the amyloidogenic protein. Figure 4 shows an inhibitory effect of BSB on formation of TTR amyloid in vitro. In the presence of BSB, TTR could not become complete fibrils; we observed only immature amyloid fibrils. Recently, the thioflavin $T$ test has been used to evaluate the degree of amyloid formation in vitro (LeVine, 1993). However, we did not analyze the effect of BSB on amyloid formation in vitro as assessed by the thioflavin $t$ test because that method examines the competitive inhibition between thioflavin T and BSB (Zhuang et al, 2001a, 2001b), and we are not aware of the true effect of BSB on amyloid formation of the TTR molecule with this method. Therefore, we used electron microscopy for our analysis. Our data suggest that BSB may become a useful tool for suppressing amyloid formation in systemic amyloidosis.

In summary, we have illustrated the usefulness of BSB for detection of amyloid deposits in vitro and in vivo, as well as the therapeutic potential for BSB in amyloidosis. BSB has only recently been developed, so information on its potential effects on the human body is not available. In vivo studies of BSB are definitely required for elucidating its potential validity for the diagnosis and treatment of amyloidosis.

\section{Materials and Methods}

\section{Subjects and Materials}

For the histopathologic examinations, autopsy samples from 10 patients with FAP (five men and five women; average $34.6 \pm 5.8$ years old) were included in the study. All patients had a definitive diagnosis of FAP ATTR Val30Met on the basis of clinical findings, amyloid deposits in biopsy specimens, and a positive test for ATTR Val30Met (Terazaki et al, 1999). One patient with AL amyloidosis (a 58-year-old woman), three patients with secondary amyloidosis (two men and one woman; average $48.6 \pm 5.6$ years old), seven patients with DRA (three men and four women; average $53.4 \pm 6.7$ years old), and one patient with familial prion disease all had diagnoses based on clinical and histopathologic findings.

\section{Histochemical Analyses}

Each tissue sample was obtained at autopsy. Sections were cut 3- $\mu \mathrm{m}$ thick from paraffin-embedded blocks of tissue and were stained with alkaline Congo red. Congo red reactivity was confirmed under polarized light (Puchtler and Sweat, 1965; Westermark et al, 1999). For BSB staining, sections were immersed in $0.01 \%$ BSB in $50 \% \mathrm{EtOH}$ for 30 minutes. Sections were quickly differentiated in saturated $\mathrm{Li}_{2} \mathrm{CO}_{3}$ and rinsed in $50 \% \mathrm{EtOH}$ before examination by fluorescence microscopy (Skovronsky et al, 2000). Rabbit anti-human TTR antibody, rabbit anti-human kappa, lambda light chain antibodies, anti-human $\mu_{2}-$ microglobulin antibody, and rabbit anti-human amyloid A component antibody (Dako, Glostrup, Denmark) were used for the immunohistochemical studies. The ABC method was used (Dako) according to the manufacturer's instructions. All chemicals used in histochemical and biochemical studies were of analytical grade.

\section{BSB Synthesis}

BSB was synthesized according to the method described by Zhuang et al (2001a, 2001b) with slight modifications. Briefly, the Wittig-Horner-Emmons reaction with 2-methoxy-5-formyl benzoic acid methyl ester and 2-bromo-1,4-bis(diethylphosphonato)xylene provided the coupled product, 1-bromo-2,5-bis(3- 
methoxycarbonyl-4-methoxy)styrylbenzene, as a 49\% yield. After deprotection with a large excess of $\mathrm{BBr}_{3}$ in dichloromethane followed by hydrolysis, BSB was obtained at a $20 \%$ overall yield, as a yellowish powder. HPLC analysis (Wakosil II 5C18HG) with a 4:1 (v/v) mixture of acetonitrile and $10 \mathrm{~mm}$ phosphate buffer $(\mathrm{pH} 7.0)$ as an eluent showed $99 \%$ purity, as detected at $254 \mathrm{~nm}$. IR (KBr): 3500, $1680 \mathrm{~cm}^{-1}$, FAB-MS: $\mathrm{m} / \mathrm{z}$ $481\left(\mathrm{M}^{+} 1\right)$, and ${ }^{1} \mathrm{H}-\mathrm{NMR}\left(300 \mathrm{MHz}\right.$, DMSO- $\left.\mathrm{d}_{6}\right)$ spectrum data were in good agreement with results reported by Zhuang et al (2001a, 2001b).

\section{Induction of AA Amyloidosis in Mice}

Complete Freund's adjuvant and Mycobacterium butyricum were from Difco Laboratories (Detroit, Michigan). AA amyloidosis was induced in C57BL/6J mice according to the method of Hoshii et al (1997). Emulsions of complete Freund's adjuvant with M. butylicum were prepared as follows: equal volumes of complete Freund's adjuvant and PBS were added to samples of M. butylicum and emulsified in the cold under sterile conditions. Aliquots of $250 \mu$ l of emulsion were injected intraperitoneally into the mice.

\section{Injection and In Vivo Characterization of BSB}

Four weeks after $250 \mu$ l of emulsion was injected into the mice, $200 \mu \mathrm{l}$ of $0.2 \%$ BSB in mouse serum was injected via the tail vein. Six mice were allowed to recover for 24 or 48 hours before they were killed by decapitation, and spleens were removed and frozen. Sections 8- to 10- $\mu \mathrm{m}$ thick were cut by cryostat, dried, and imaged with no additional staining. After sections were imaged, serial sections were stained with Congo red.

\section{Amyloid Formation in Human TTR}

Denatured TTR was generated by the procedure of Goldberg et al (1991). To evaluate amyloid fibril formation via partial TTR denaturation, $15 \mu \mathrm{M}$ TTR was mixed in $50 \mathrm{~mm}$ sodium acetate (pH 3.0-4.0) containing $100 \mathrm{~mm} \mathrm{KCl}$, with or without $20 \mu \mathrm{M} \mathrm{BSB}$, and incubated with agitation at $37^{\circ} \mathrm{C}$ for 4 weeks.

\section{Affinity of BSB or Congo Red for Amyloid Fibrils}

FAP amyloid fibrils were collected by centrifugation from vitrectomized corpus vitreum from patients with FAP. The samples were then washed three times with $1 \mathrm{ml}$ of saline and $1 \mathrm{ml}$ of distilled water, respectively, and were centrifuged ( $9000 \times g$ for 5 minutes) (Ando et al, 1999). DRA amyloid fibrils were purified from an intestinal sample from a patient as described by Naiki et al (1989). The affinity of BSB or Congo red for amyloid fibrils was examined by using a highly sensitive 27-MHz QCM (Affinix Q; litium Company, Tokyo, Japan) as described (Matsuno et al, 2001; Okahata et al, 1998). Briefly, $2 \mu \mathrm{l}$ of $100 \mu \mathrm{g} / \mathrm{ml}$ purified amyloid fibrils, $2 \mu$ of $100 \mu \mathrm{g} / \mathrm{ml}$ purified wild-type TTR, or the variant TTR (ATTR Val30Met) was directly immobilized on a QCM plate, the plate was soaked in $6 \mathrm{ml}$ of a buffered solution [10 mm Tris- $\mathrm{HCl}, 10 \%$ dimethyl sulfoxide (DMSO), $\mathrm{pH} \mathrm{7.4]} \mathrm{at} 25^{\circ} \mathrm{C}$, and the resonance frequency of the QCM was defined as the 0 position after equilibrium. Then, BSB or Congo red solution (dissolved in 10\% DMSO) was injected silently into the buffered solution, and time courses of the change in frequency of the QCM responding to BSB or Congo red was recorded. The stability and drift of the $27-\mathrm{MHz}$ QCM frequency in the solution were $\pm 5 \mathrm{~Hz}$ for 12 hours at $25^{\circ} \mathrm{C}$.

\section{Electron Microscopic Analyses}

The sample containing the synthesized TTR filaments was centrifuged at $15,000 \times g$ for 90 minutes. Pellets were placed on collodion-coated grids and negatively stained with $2 \%$ phosphotungstic acid adjusted to $\mathrm{pH}$ 7.4. The specimens were examined under a Hitachi H7000 electron microscope (Hitachi Company, Hitachi, Japan) with an accelerating voltage of $100 \mathrm{kV}$.

\section{Acknowledgements}

We thank the Trustees of the University of Pennsylvania for providing a significant amount of BSB to perform the experiments.

\section{References}

Ando Y, Ando E, Ohlsson PI, Olofsson Å, Sandgren O, Suhr $\mathrm{O}$, Terazaki H, Obayashi K, Lundgren E, Ando M, and Negi A (1999). Analysis of transthyretin (TTR) forms of amyloid fibrils from vitreous samples in familial amyloidotic polyneuropathy (Met30). Amyloid 6:119-123.

Ando $\mathrm{Y}$, Nakamura $\mathrm{M}$, Kai $\mathrm{H}$, Katsuragi $\mathrm{S}$, Terazaki $\mathrm{H}$, Nozawan T, Okuda T, Misumi S, Matsunaga N, Tajiri T, Shoji S, Yamashita T, Haraoka K, Obayashi K, Matsumoto K, Ando M, and Uchino M (2002). A novel localized amyloidosis associated with lactoferrin in the cornea. Lab Invest 82:757766.

Benditt EP, Eriksen N, and Berglund C (1970). Congo red dichroism with dispersed amyloid fibrils, an extrinsic cotton effect. Proc Natl Acad Sci USA 66:1044-1051.

Benson MD (1995). Amyloidosis. In: Scriver CR, Beaudet AK, Sly WS, and Valle D, editors. The metabolic and molecular bases of inherited disease. New York: McGraw-Hill, 41594191.

Benson MD, Liepnieks J, Uemichi T, Wheeler G, and Correa R (1993). Hereditary renal amyloidosis associated with a mutant fibrinogen-chain. Nat Genet 3:252-255.

Benson MD and Uemichi T (1996). Transthyretin amyloidosis. Amyloid 3:44-56.

Bi W, Hayes RB, Feng P, Qi Y, You X, Zhen J, Zhang M, Qu B, Fu Z, Chen M, Co Chien HT, and Blot WJ (1992). Mortality and incidence of bladder cancer in benzidine-exposed workers in China. Am J Ind Med 21:481-489.

Case RAM, Hosker MW, McDonald DB, and Pearson JT (1954). Tumors of the urinary bladder in workmen engaged in the manufacture and use of certain dyestuff intermediates in the British chemical industry. $\mathrm{Br} \mathrm{J}$ Ind Med 11:75-104.

Dezutter NA, Dom RJ, de Groot TJ, Bormans GM, and Verbruggen AM (1999). ${ }^{99 m}$ Tc-MAMA-chrysamine $\mathrm{G}$, a probe 
for beta-amyloid protein of Alzheimer's disease. Eur $\mathrm{J}$ Nucl Med 26:1392-1399.

Dezutter NA, Landman WJ, Jager PL, de Groot TJ, Dupont PJ, Tooten PC, Zekarias B, Gruys E, and Verbruggen AM (2001a). Evaluation of ${ }^{99 \mathrm{~m}}$ Tc-MAMA-chrysamine $\mathrm{G}$ as an in vivo probe for amyloidosis. Amyloid 8:202-214.

Dezutter NA, Sciot RM, de Groot TJ, Bormans GM, and Verbruggen AM (2001b). In vitro affinity of ${ }^{99} \mathrm{Tcm}$-labelled N2S2 conjugates of chrysamine $G$ for amyloid deposits of systemic amyloidosis. Nucl Med Commun 22:553-558.

Giger M, Baumgartner HR, and Zbinden G (1974). Toxicological effects of Evans blue and Congo red on blood platelets. Agents Actions 4:173-180.

Giger M and Zbinden G (1974). Significance of the albumin concentration for the toxic effect of Evans blue and Congo red on thrombocytes. Schweiz Med Wochenschr 104:13761377.

Goldberg ME, Rudolph R, and Jaenicke R (1991). A kinetic study of the competition between renaturation and aggregation during the refolding of denatured-reduced 197-egg white lysozyme. Biochemistry 30:2790-2797.

Guy CD and Jones CK (2001). Abdominal fat pad aspiration biopsy for tissue confirmation of systemic amyloidosis: Specificity, positive predictive value, and diagnostic pitfalls. Diagn Cytopathol 24:181-186.

Hachulla E, Deveaux M, Duquesnoy B, and Marchandise X (1994). Scintigraphy using amyloid $P$ component labelled with iodine 123: A new method of evaluation of amyloidosis. Presse Med 23:348.

Hachulla E, Maulin L, Deveaux M, Facon T, Bletry O, Vanhille P, Wechsler B, Godeau P, Levesque H, Hatron PY, Huglo D, Devulder B, and Marchandise X (1996). Prospective and serial study of primary amyloidosis with serum amyloid $P$ component scintigraphy: From diagnosis to prognosis. Am J Med 101:77-87.

Hawkins PN, Lavender JP, and Pepys MB (1990). Evaluation of systemic amyloidosis by scintigraphy with ${ }^{123}$ /-labeled serum amyloid P component. N Engl J Med 323:508-513.

Hoshii Y, Kawano H, Cui D, Takeda T, Gondo T, Takahashi M, Kogishi K, Higuchi K, and Ishihara T (1997). Amyloid A protein amyloidosis induced in apolipoprotein-E-deficient mice. Am J Pathol 151:911-917.

Ikeda S, Nakazato M, Ando Y, and Sobue G (2002). Familial transthyretin-type amyloid polyneuropathy in Japan: Clinical and genetic heterogeneity. Neurology 58:1001-1007.

Ishihara T, Nagasawa T, Yokota T, Gondo T, Takahashi M, and Uchino $F$ (1989). Amyloid protein of vessels in leptomeninges, cortices, choroid plexuses, and pituitary glands from patients with systemic amyloidosis. Hum Pathol 20:891-895.

Kaplan B, Vidal R, Kumar A, Ghiso J, and Gallo G (1999). Immunochemical microanalysis of amyloid proteins in fineneedle aspirates of abdominal fat. Am J Clin Pathol 112:403407.

Kennelly JC, Shaw A, and Martin CN (1984). Reduction to benzidine is not necessary for the covalent binding of a benzidine azodye to rat liver DNA. Toxicology 32:315-324.

Klunk WE, Debnath ML, Koros AM, and Pettegrew JW (1998). Chrysamine-G, a lipophilic analogue of Congo red, inhibits $A$ beta-induced toxicity in PC12 cells. Life Sci 63:1807-1814.
Klunk WE, Debnath ML, and Pettegrew JW (1994). Development of small molecule probes for the beta-amyloid protein of Alzheimer's disease. Neurobiol Aging 15:691-698.

Klunk WE, Debnath ML, and Pettegrew JW (1995). Chrysamine-G binding to Alzheimer and control brain: Autopsy study of a new amyloid probe. Neurobiol Aging 16: 541-548.

LeVine H 3rd (1993). Thioflavine T interaction with synthetic Alzheimer's disease beta-amyloid peptides: Detection of amyloid aggregation in solution. Protein Sci 2:404-410.

Masouye I (1997). Diagnostic screening of systemic amyloidosis by abdominal fat aspiration: An analysis of 100 cases. Am J Dermatopathol 19:41-45.

Matsuno H, Niikura K, and Okahata Y (2001). Direct monitoring kinetic studies of DNA polymerase reactions on a DNAimmobilized quartz-crystal microbalance. Chemistry 7:33053312 .

Moran JK (1999). Technetium-99m-EC and other potential new agents in renal nuclear medicine. Semin Nucl Med 29:91-101.

Naiki H, Higuchi K, Hosokawa M, and Takeda T (1989). Fluorometric determination of amyloid fibrils in vitro using the fluorescent dye, thioflavin T1. Anal Biochem 177:244-249.

Okahata $Y$, Niikura K, Sugiura $Y$, Sawada $M$, and Morii $T$ (1998). Kinetic studies of sequence-specific binding of GCN4-bZIP peptides to DNA strands immobilized on a 27-MHz quartz-crystal microbalance. Biochemistry 37:56665672.

Pepys MB, Hawkins PN, Booth DR, Vigushin DM, Tennent GA, Soutar AK, Totty N, Nguyen O, Blake CC, Terry CJ, Feest TG, Zalin AM, and Hsuan JJ (1993). Human lysozyme gene mutations cause hereditary systemic amyloidosis. Nature 362:553-557.

Puchtler H and Sweat F (1965). Congo red as a stain for fluorescence microscopy of amyloid. J Histochem Cytochem 13:693-694.

Puille M, Altland K, Linke RP, Steen-Muller MK, Klett R, Steiner D, and Bauer R (2002). ${ }^{99 m}$ Tc-DPD scintigraphy in transthyretin-related familial amyloidotic polyneuropathy. Eur J Nucl Med 29:376-379.

Rydh A, Suhr O, Hietala SO, Ahlstrom KR, Pepys MB, and Hawkins PN (1998). Serum amyloid P component scintigraphy in familial amyloid polyneuropathy: Regression of visceral amyloid following liver transplantation. Eur J Nucl Med 25:709-713

Saile R, Deveaux M, Hachulla E, Descamps J, Duquesnoy B, and Marchandise X (1993). lodine-123-labelled serum amyloid $\mathrm{P}$ component scintigraphy in amyloidosis. Eur $\mathrm{J}$ Nucl Med 20:130-137.

Saraiva MJ (2001). Transthyretin mutations in hyperthyroxinemia and amyloid diseases. Hum Mutat 17:493-503.

Sauerbrey G (1959). Verwendung von Schwingquarzed zur Wagung dunner Schichten und zur Mikrowagung. Z Phys Vlo 155:206.

Schmidt ML, Schuck T, Sheridan S, Kung MP, Kung H, Zhuang ZP, Bergeron C, Lamarche JS, Skovronsky D, Giasson BI, Lee VM, and Trojanowski JQ (2001). The fluorescent Congo red derivative, (trans, trans)-1-bromo-2,5-bis-(3hydroxycarbonyl-4-hydroxy)styrylbenzene (BSB), labels diverse beta-pleated sheet structures in postmortem human 
neurodegenerative disease brains. Am J Pathol 159:937943.

Sipe JD and Cohen AS (2000). Review: History of the amyloid fibril. J Struct Biol 130:88-98.

Skovronsky DM, Zhang B, Kung MP, Kung HF, Trojanowski $J Q$, and Lee VM (2000). In vivo detection of amyloid plaques in a mouse model of Alzheimer's disease. Proc Natl Acad Sci USA 97:7609-7614.

Soutar AK, Hawkins PN, Vigushin DM, Tennent GA, Booth SE, Hutton T, Nguyen O, Totty NF, Feest TG, Hsuan JJ, and Pepys MB (1992). Apolipoprotein Al mutation Arg-60 causes autosomal dominant amyloidosis. Proc Natl Acad Sci USA 89:7389-7393.

Tan SY and Pepys MB (1994). Amyloidosis. Histopathology 25:403-414.

Tan SY, Pepys MB, and Hawkins PN (1995). Treatment of amyloidosis. Am J Kidney Dis 26:267-285.

Terazaki H, Ando Y, Misumi S, Nakamura M, Ando E, Matsunaga N, Shoji S, Okuyama M, Ideta H, Nakagawa K, Ishizaki T, Ando M, and Saraiva MJ (1999). A novel compound heterozygote (FAP ATTR Arg104His/ATTR Val30Met) with high serum transthyretin (TTR) and retinol binding protein (RBP) levels. Biochem Biophys Res Commun 264:365370.
Westermark GT, Johnson KH, and Westermark P (1999). Staining methods for identification of amyloid in tissue. Methods Enzymol 306:3-25.

Westermark GT and Westermark P (2000). Endocrine amyloid: A subject of increasing interest for the next century. Amyloid 71:19-22.

Westermark P, Benson MD, Buxbaum JN, Cohen AS, Frangione B, Ikeda S, Masters CL, Merlini G, Saraiva MJ, and Sipe JD (2002). Amyloid fibril protein nomenclature-2002. Amyloid 9:197-200.

Zenser TV, Lakshmi VM, and Davis BB (1998). $\mathrm{N}$-glucuronidation of benzidine and its metabolites: Role in bladder cancer. Drug Metab Dispos 26:856-859.

Zhuang ZP, Kung MP, Hou C, Plossl K, Skovronsky D, Gur TL, Trojanowski JQ, Lee VM, and Kung HF (2001a). IBOX(2(4'-dimethylaminophenyl)-6-iodobenzoxazole): A ligand for imaging amyloid plaques in the brain. Nucl Med Biol 28:887894.

Zhuang ZP, Kung MP, Hou C, Skovronsky DM, Gur TL, PlossI K, Trojanowski JQ, Lee VM, and Kung HF (2001b). Radioiodinated styrylbenzenes and thioflavins as probes for amyloid aggregates. J Med Chem 44:1905-1914. 